\title{
INFLUENCE OF HIGH ALTITUDE ON COMBUSTION EFFICIENCY AND RADIATION FRACTION OF HYDROCARBON FIRES
}

\author{
Haihang Li, ${ }^{1,2}$ Wei Yao, ${ }^{3}$ Pan Li, ${ }^{1}$ Zhihui Zhou, ${ }^{1,4}$ E Jian Wang ${ }^{1, *}$ \\ ${ }^{1}$ State Key Laboratory of Fire Science, University of Science and Technology of China, \\ Hefei 230026, Anhui, P.R. China \\ ${ }^{2}$ Safety and Environment Institute, College of Quality \& Safety Engineering, China Jiliang \\ University, Hangzhou 310018, P.R. China \\ ${ }^{3}$ Institute of Mechanics, Chinese Academy of Sciences, Beijing 100190, P.R. China \\ ${ }^{4}$ China Waterborne Transport Research Institute, Beijing 100088, P.R. China \\ *Address all correspondence to: Jian Wang, E-mail: wangj@ustc.edu.cn \\ Original Manuscript Submitted: 11/1/2013; Final Draft Received: 9/7/2015
}

Fire behaviors of three gaseous hydrocarbon fuels were experimentally measured and compared at two different altitudes (Lhasa city, $64 \mathrm{kPa}$ at an altitude of $3650 \mathrm{~m}$; Hefei city, $100 \mathrm{kPa}$ at an altitude of $50 \mathrm{~m}$ ). The heat release rates were calculated through a simplified thermochemistry based on the measured concentrations of $\mathrm{O}_{2}$ and $\mathrm{CO}_{2}$ in the exhaust duct, then the combustion efficiencies and the radiation fractions were compared at the two altitudes. The heat release rates and combustion efficiencies were higher at lower pressure, and the overall temperatures of methane fires rose at a lower pressure. The radiative heat fluxes and radiation fractions at a low pressure were smaller than those at a normal pressure, while the smoke transmittances of acetylene fires at a low pressure were higher.

KEY WORDS: hydrocarbon fire, heat release rate, combustion efficiency, radiation fraction, transmittance

\section{INTRODUCTION}

Fire behavior research at a low pressure has been a hotspot recently to meet the fire protection requirements in plateau districts and cruising airplanes. Previous studies showed that ambient pressure has a significant influence on combustion behaviors such as burning rate (Yao, 2013; Yin et al., 2013), flame shape (Tao et al., 2013), flame radiation flux, and product concentrations (Jun et al., 2008). The plateau regions provide low atmospheric pressure conditions to investigate flame and smoke characteristics.

Wieser et al. (1997) carried out solid and liquid fire tests in a mobile room at altitudes from $400 \mathrm{~m}$ to $3000 \mathrm{~m}$ and showed that the burning rate varies as the 1.3 power of pressure. Based on both theoretical analysis and experimental measurements, Nikitin (1998) reported that the mass combustion rate is proportional to the gas pressure raised to the two-thirds power. Jun et al. 2008 concluded that the ratios of the average burning rates of $n$-heptane fires in Lhasa to Hefei approaches approximately the air pressure ratio of Lhasa to Hefei, i.e., 0.64. Li et al. (2009) investigated wood and $n$-heptane fires at two altitudes $(50 \mathrm{~m}$ and $3650 \mathrm{~m}$ ) and found that the ratio of burning rates at these two pressures coincides with the conclusion of Wieser et al. (1997). In order to compare the combustion behaviors at two altitudes for the same burning rate, Li et al. (2009) employed larger $n$-heptane pan tests and reported that the flame radiation flux is lower while the average flame 


\begin{tabular}{|c|c|c|c|}
\hline \multicolumn{4}{|c|}{ NOMENCLATURE } \\
\hline$A$ & $\begin{array}{l}\text { coefficient ratio of } \mathrm{CO}_{2} \text { to } \mathrm{O}_{2} \text { in global } \\
\text { reaction equation }\end{array}$ & $\begin{array}{l}K \\
L\end{array}$ & $\begin{array}{l}\text { light extinction coefficient, } \mathrm{m}^{-1} \\
\text { optical path length, } \mathrm{m}\end{array}$ \\
\hline$a, b, c$ & coefficients in global reaction equation & & fuel mass loss rate, $\mathrm{kg} / \mathrm{s}$ \\
\hline$C_{x} H_{y}$ & hydrocarbon consisting of $x$ carbon atoms & $\dot{Q}$ & heat release rate, $\mathrm{HRR}, \mathrm{kW}$ \\
\hline & and $y$ hydrogen atoms & $\dot{Q}_{r}$ & overall radiative heat flux, $\mathrm{kW}$ \\
\hline$\Delta H$ & enthalpy of reaction for per unit mass & $q_{r}$ & radiative heat flux per unit area, $\mathrm{kW} / \mathrm{m}^{2}$ \\
\hline & fuel in incomplete combustion, $\mathrm{kJ} / \mathrm{kg}$ & $R$ & distance from flame center to the \\
\hline$\Delta H_{c}$ & heat of combustion, i.e., enthalpy of reaction & & radiometer, $\mathrm{m}$ \\
\hline & $\begin{array}{l}\text { for per unit mass fuel in complete } \\
\text { combustion, } \mathrm{kJ} / \mathrm{kg}\end{array}$ & & symbols \\
\hline$I$ & received light intensity & $\chi$ & combustion efficiency \\
\hline$I_{0}$ & incident light intensity & $\chi_{r}$ & radiation fraction \\
\hline
\end{tabular}

temperature is higher at a high altitude. The subsequent experimental investigation conducted at a higher altitude of $4250 \mathrm{~m}$ by $\mathrm{Hu}$ et al. (2011) confirmed the findings for the burning rate and combustion behaviors made in Li et al. (2009).

The burning rate or mass loss rate, as a primary parameter of solid and liquid fuel fires and a governing factor that influence the combustion behaviors, has been inevitably investigated in these previous works (Hu et al., 2011; Jun et al., 2008; Li et al., 2009; Nikitin, 1998; Wieser et al., 1997; Yao, 2013; Yin et al., 2013). So a gaseous fuel of acetylene was used by Yang et al. (2012) to obtain exactly the same burning rate at two altitudes $(50 \mathrm{~m}$ and $3650 \mathrm{~m})$ in a more recent work. But in fact, the effective heat release rate or combustion efficiency are likely to be different under various buoyancy conditions for the same burning rate at different pressures. The combustion efficiency generally depends on fuel type, flame size, soot production, and ventilation condition (Tewarson, 2004). The combustion efficiency usually ranges from unity to the lowest value 0.46 reported in Tewarson (2002). The products of incomplete combustion are usually CO, soot, and unburnt hydrocarbons (e.g., aromatics, aldehydes).

From this point of view, the product composition and concentration reflect the completeness of combustion. In the case of hydrocarbon fuels, a higher combustion efficiency means that carbon in the fuel ends up with more $\mathrm{CO}_{2}$, and less $\mathrm{CO}$, soot and other unburnt hydrocarbons (Bourguignon et al., 1999). Koseki and Mulholland (1991) employed the ratio of $\mathrm{CO} / \mathrm{CO}_{2}$ and smoke yield as measures of the combustion efficiency, and a high level of $\mathrm{CO}$ concentration as a sign of poor combustion efficiency (X1, x1). The different CO concentrations in Lhasa and Hefei tests (Jun et al., 2008) indicated that the ambient pressure exerts some influence on combustion efficiency. These parameters, the so-called carbon conversion expressions, mentioned above are compromized and qualitative measures of combustion efficiency. However, the quantitatively and traditionally measured combustion efficiency, defined as the chemical heat of combustion divided by the net heat of complete combustion (Tewarson, 2002), has not been revealed at different pressures in the past and is to be evaluated in this paper. 
In the present work, fire tests of three gaseous hydrocarbon fuels were carried out at two different altitudes, $3650 \mathrm{~m}$ in Lhasa $(64 \mathrm{kPa})$ and $50 \mathrm{~m}$ in Hefei $(100 \mathrm{kPa})$. The heat release rates were calculated based on concentrations of $\mathrm{O}_{2}$ and $\mathrm{CO}_{2}$. The combustion efficiencies and radiation efficiencies at the two altitudes were compared to reveal the influence of pressure on the fire characteristics.

\section{EXPERIMENTAL SETUP AND PROCEDURE}

\subsection{Test Platform}

The fire tests were conducted on a scaled platform 0.4 times the size of ISO9705 fire test platform (ISO $9705,1993)$ in Lhasa $(64 \mathrm{kPa}, 3650 \mathrm{~m})$ and Hefei $(100 \mathrm{kPa}, 50 \mathrm{~m})$, as shown in Fig. 1. The platforms were located in large enough spaces to ensure full development of fires in a windless environment. The dimensions of the cone body are 1.2-m long, 1.2-m wide, and 1.2-m high. Glazed windows were embedded in the upper part of the cone body to facilitate experimental observation, while the lower part was vacant to entrain fresh air. The exhaust hood and duct were designed to collect and pump out combustion products. Two baffles in the top of the hood and two guide vanes at both ends of the duct were designed to mix the products uniformly for more accurate sampling measurements. A fan volumetric flow rate of $0.18 \mathrm{~m}^{3} / \mathrm{s}$ was found enough to exhaust the combustion products in both Lhasa and Hefei through the ducts with internal diameter of $0.16 \mathrm{~m}$.

Fuels were supplied from compressed cylinders and regulated by a thermal mass flow controller, then through a stainless steel burner with $50 \mathrm{~mm}$ inner diameter located at the center of the cone base. The Sevenstar D07-19B flow controller has a measure range of 0-30 slm and a resolution of $0.1 \mathrm{slm}$. The measure accuracy of mass flow rate is within $\pm 1 \%$ and the repeatability is $\pm 0.2 \%$. Heat-resistant glass beads in the

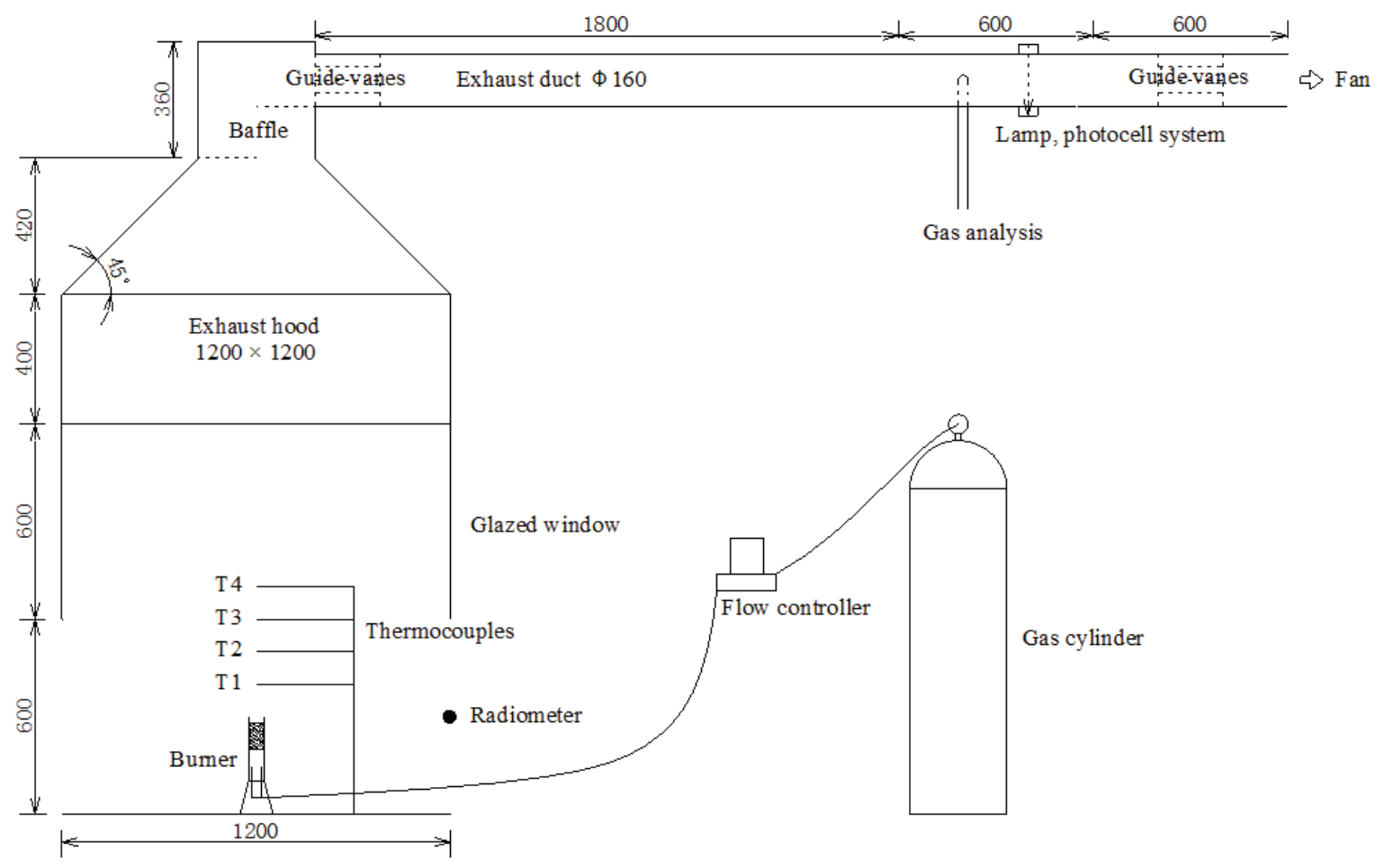

FIG. 1: The test platform and instrumentation layout 
burner tube were used to stabilize the flame and make the velocity profile at the exit uniform. Three hydrocarbon fuels with increasing carbon ratio were selected to be methane, propane, and acetylene with industrial purities $\geq 99.9 \%$.

\subsection{Measuring Instruments}

The concentrations of oxygen and carbon dioxide flowing through the exhaust duct were measured by a Servomex 4100 analyzer based on principles of paramagnetic and infrared ray, respectively. The ranges for measuring oxygen and carbon dioxide are $0-25 \%$ and $0-10 \%$, respectively, both with $\pm 0.001 \%$ resolution. An array of four K-type thermocouples with $0.5 \mathrm{~mm}$ bead diameter labeled as T1-T4 were vertically distributed along the burner axis, with a spacing of $10 \mathrm{~cm}$ and the lowest thermocouple $\mathrm{T} 1$ was $10 \mathrm{~cm}$ above the burner exit. A wide angle water-cooled radiometer was placed at the same elevation as the burner exit and $55 \mathrm{~cm}$ horizontal distance from the edge of the burner to measure the ensemble emitted radiation flux from the fires. The horizontal distance is 11 times the diameter of the burner so that the point source model would be suitable (Hamins et al., 1991; Markstein, 1985). A photoelectric kapnometer mainly consisting of a lamp and photocell was mounted on the exhaust duct to measure the smoke transmittance. The sampling rates of the thermocouples and radiometer are both $1 \mathrm{~Hz}$, while the sampling rates of the gas analyzer and kapnometer are $3 \mathrm{~Hz}$.

\subsection{Test Cases}

The fuel flow rates of methane, acetylene, and propane were designed to obtain specified heat release rates of 4,8 , and $12 \mathrm{~kW}$ assuming the fuel was fully burned to carbon dioxide, as listed in Table 1 . The test for each different fuel and flow rate lasted more than $100 \mathrm{~s}$ and was repeated three times to ensure reproducibility. The environmental temperature and humidity of all the tests were approximately the same, i.e., room temperature of $18-23^{\circ} \mathrm{C}$ and relative humidity of $50-62 \%$.

\section{RESULTS AND DISCUSSION}

\subsection{Thermochemistry Technique}

Assuming that the fuel is partially converted to carbon dioxide and carbon monoxide, the total heat release rate can be calculated by a thermochemistry technique (Enright, 1999) by only measuring two of the three concentrations of $\mathrm{O}_{2}, \mathrm{CO}_{2}$, and $\mathrm{CO}$ in the exhaust duct. The thermochemistry technique is only suitable for the known fuel composition. In this study, the volumetric concentrations of $\mathrm{O}_{2}$ and $\mathrm{CO}_{2}$ in the exhaust duct are measured, then the volumetric concentration of $\mathrm{CO}$ can be calculated from the global reaction:

$$
a C_{x} H_{y}+1 \mathrm{O}_{2}=A \mathrm{CO}_{2}+b \mathrm{CO}+c \mathrm{H}_{2} \mathrm{O},
$$

TABLE 1: Summary of test conditions

\begin{tabular}{|c|c|c|}
\hline Fuel & Specified HRR, $\mathbf{k W}$ & Fuel Flow Rate, $\mathbf{g} / \mathbf{s}$ \\
\hline Methane & $4,8,12$ & $0.080,0.160,0.240$ \\
\hline Acetylene & $4,8,12$ & $0.083,0.166,0.249$ \\
\hline Propane & $4,8,12$ & $0.086,0.172,0.259$ \\
\hline
\end{tabular}


where $A$ is the mole of $\mathrm{CO}_{2}$ produced per unit mole of $\mathrm{O}_{2}, A$ can be determined by the increment of $\mathrm{CO}_{2}$ divided by the decrement of $\mathrm{O}_{2}$ during the combustion process. The other coefficients $a, b$, and $c$ can be calculated

by the conservation of atoms for $\mathrm{C}, \mathrm{H}$, and $\mathrm{O}$, as $a=\frac{4-2 A}{2 x+y}, b=\frac{4 x-4 A x-y A}{2 x+y}$, and $c=\frac{2 y-y A}{2 x+y}$.

Finally, the total heat release rate is calculated from the enthalpy of reaction and the flow rate

$$
\dot{Q}=\dot{m} \Delta H,
$$

where $\dot{m}$ is the fuel mass loss rate and $\Delta H$ is the enthalpy of reaction representing the change of enthalpy between the products and reactants. The combustion efficiency $\chi$ is calculated as the ratio of the enthalpy of reaction to the heat of combustion:

$$
\chi=\frac{\Delta H}{\Delta H_{c}},
$$

where the heat of combustion $\Delta H_{c}$ is the enthalpy of reaction when the hydrocarbon fuel is completely converted to carbon dioxide without any carbon monoxide formed.

\subsection{Heat Release Rate and Combustion Efficiency}

The flow rates corresponding to $4 \mathrm{~kW}, 8 \mathrm{~kW}$, and $12 \mathrm{~kW}$ were adjusted continuously for the same fuel, as shown in Fig. 2. The steady stage for each flow rate lasted for at least $100 \mathrm{~s}$ for taking average; for instance, the average oxygen concentration of the $4 \mathrm{~kW}$ fire was averaged from $138 \mathrm{~s}$ to $240 \mathrm{~s}$. In the sebsequent analysis, the measured quantities including concentrations, radiation flux, and transmittance were all averaged on each steady stage in both Hefei and Lhasa tests.

After determining the values of A in Eq. (1) as the variation ratios of the carbon dioxide concentration to the oxygen concentration for each test case, the heat release rates calculated from Eq. (2) were plotted in Figs. 3-5, where the heat release rates were all higher in Lhasa than in Hefei. The combustion efficiency was plotted along in Figs. 3-5 to characterize the completeness of sensible energy release under different combustion conditions. The combustion efficiencies were higher in Lhasa than in Hefei for all the test cases. The combustion efficiency increases from methane to propane to ethylene. The $\chi$ of methane is close to unity and

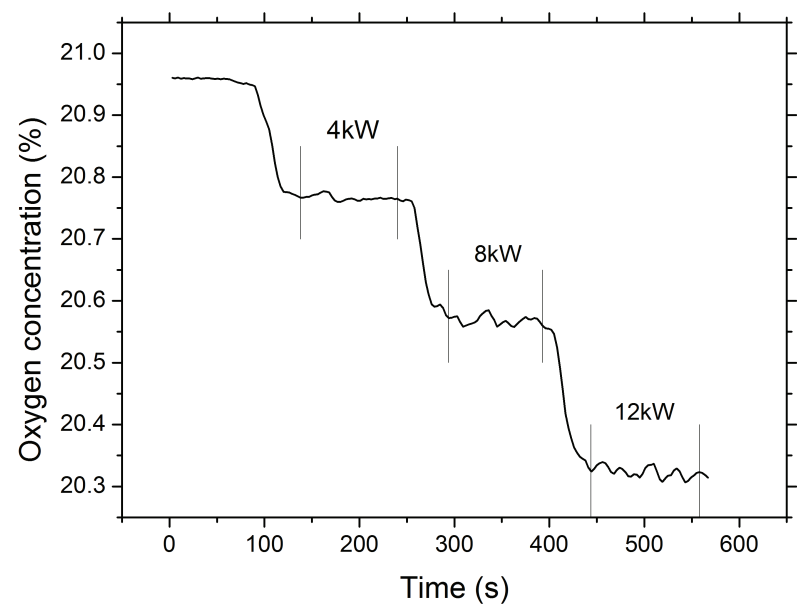

FIG. 2: An example for data reduction 


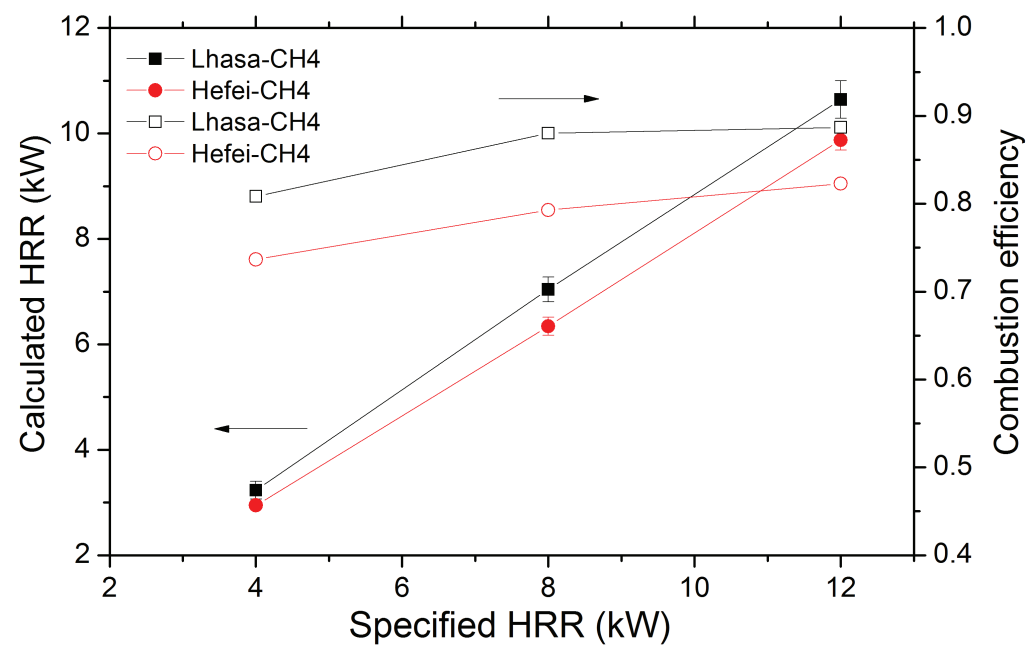

(a)

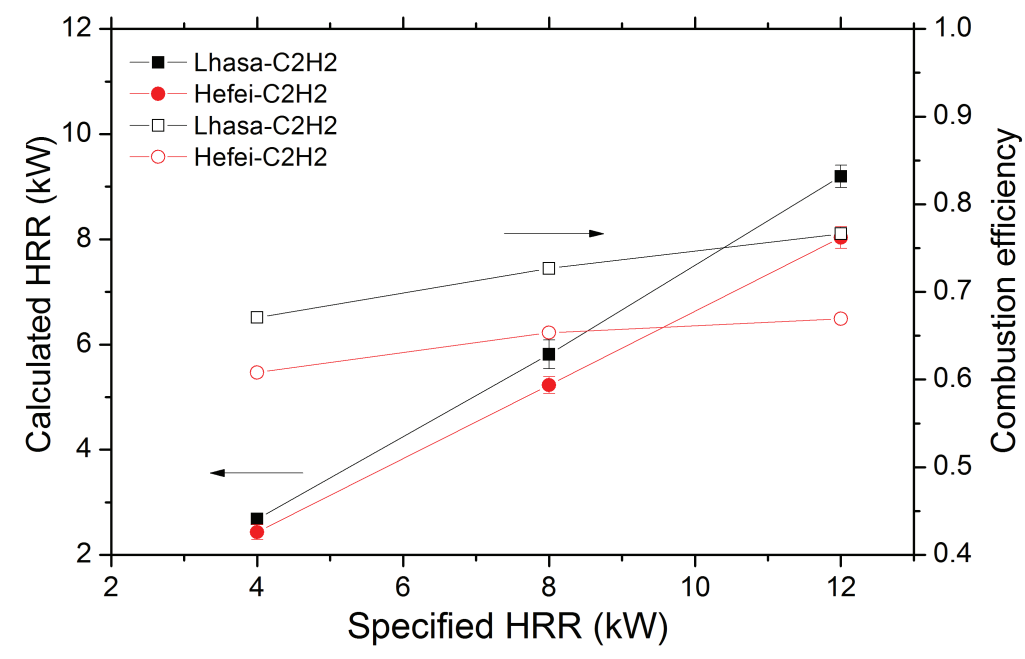

(b)

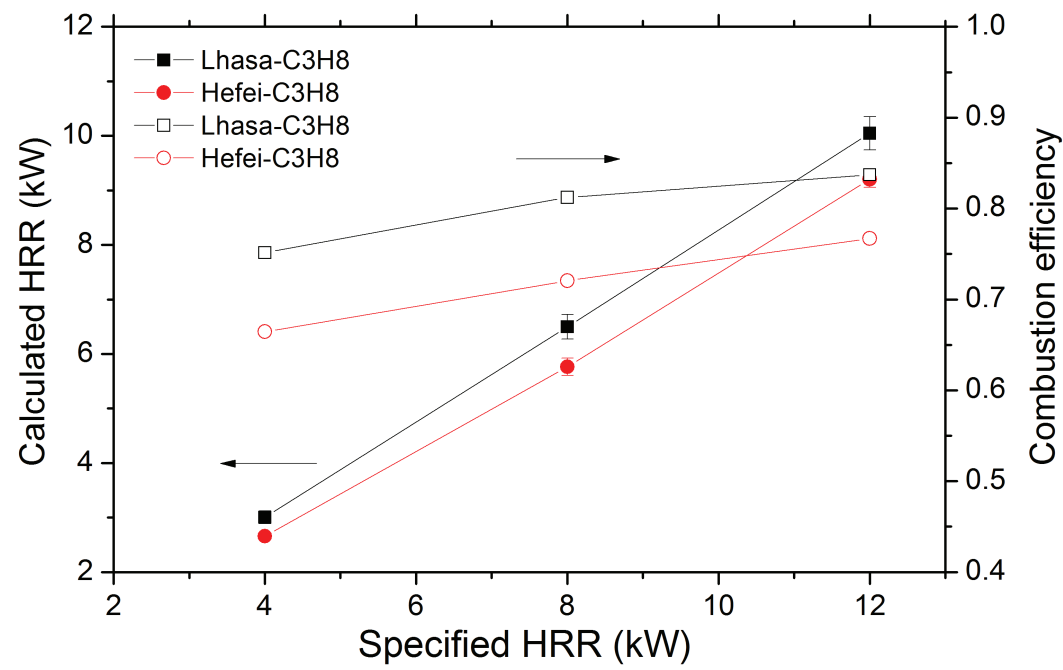

(c)

FIG. 3: Calculated HRR and combustion efficiency of fires: (a) methane fires, (b) acetylene fires, (c) propane fires 

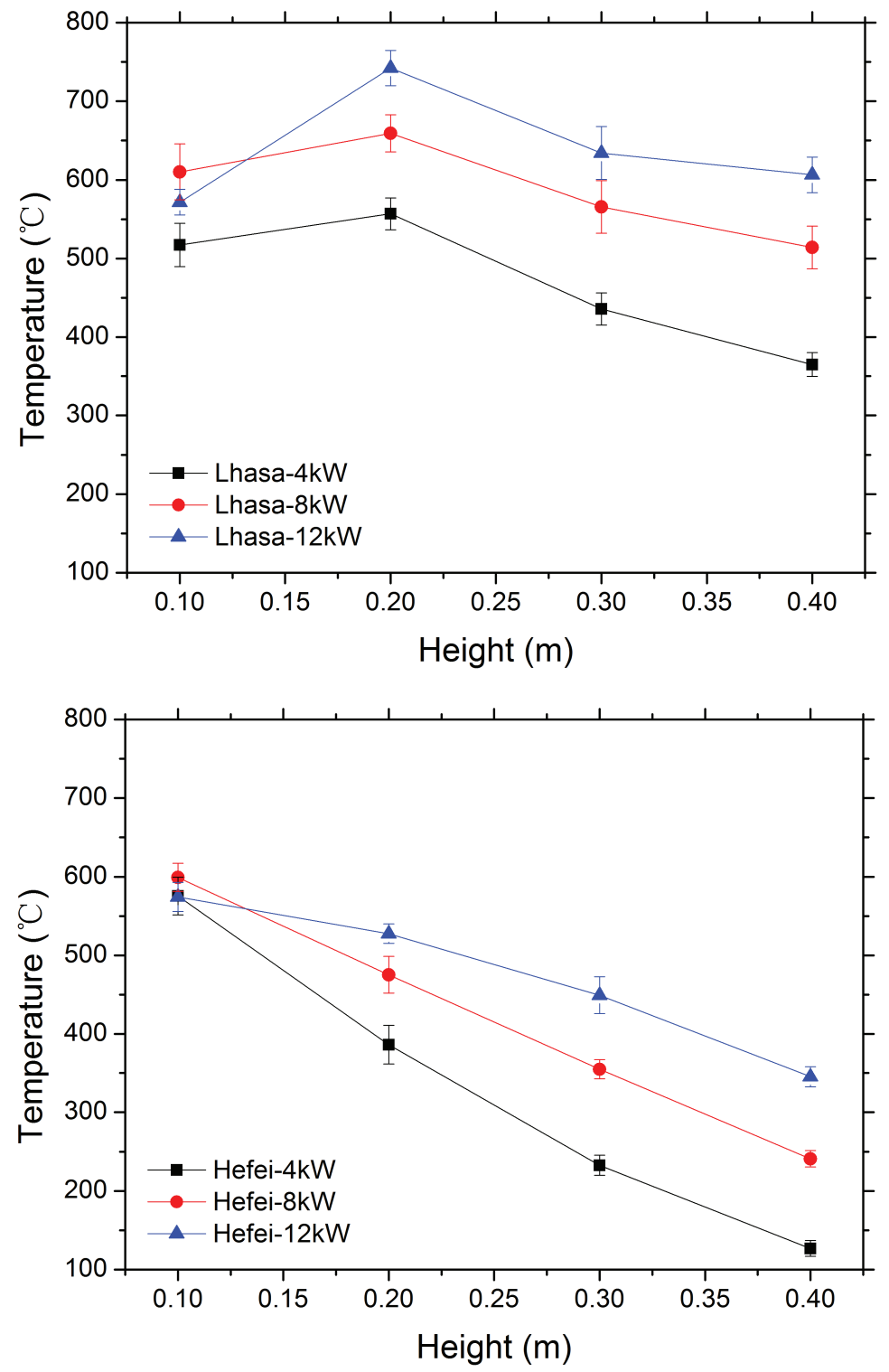

FIG. 4: Axial temperature distribution of methane fires at two altitudes: (a) temperatures at low pressure in Lhasa, (b) temperature at high pressure in Hefei

that of acetylene is approximately 0.75 as previously given in Janssens (2002). The combustion efficiencies in Hefei are lower since the carbon dioxide concentrations were observed to be lower and the flames were more sooty. Besides, flame expansion and higher temperature will result in higher combustion efficiency in Lhasa, which will be discussed below.

\subsection{Axial Temperature}

The time-averaged axial temperature of methane fires under the two pressures was plotted in Fig. 4, where the overall plume temperature is greater at a low pressure than at a normal pressure as validated in previous 


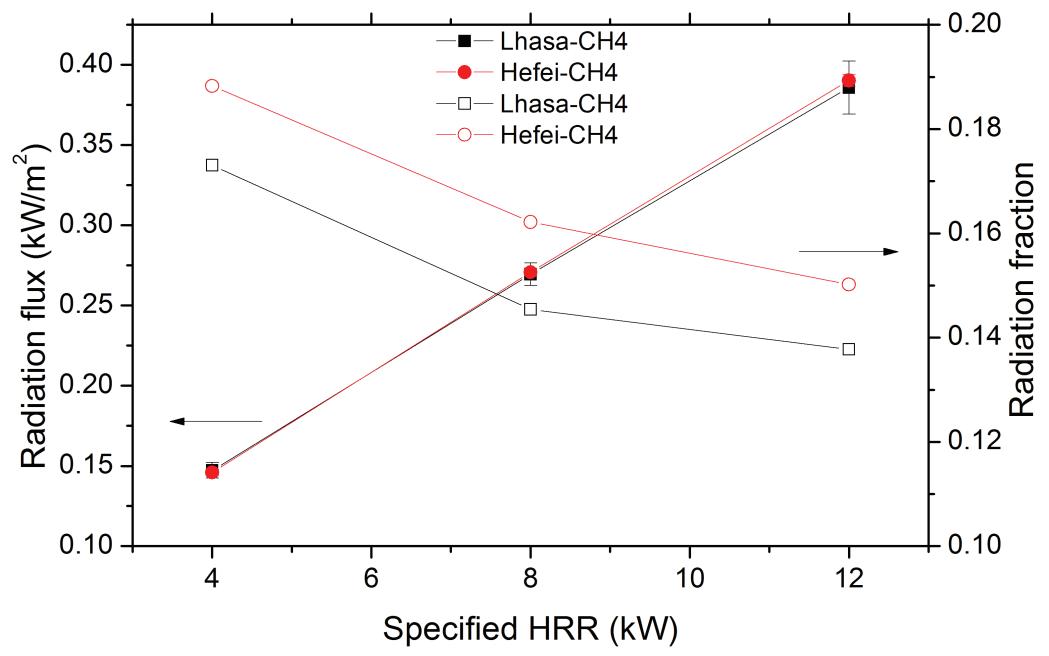

(a)

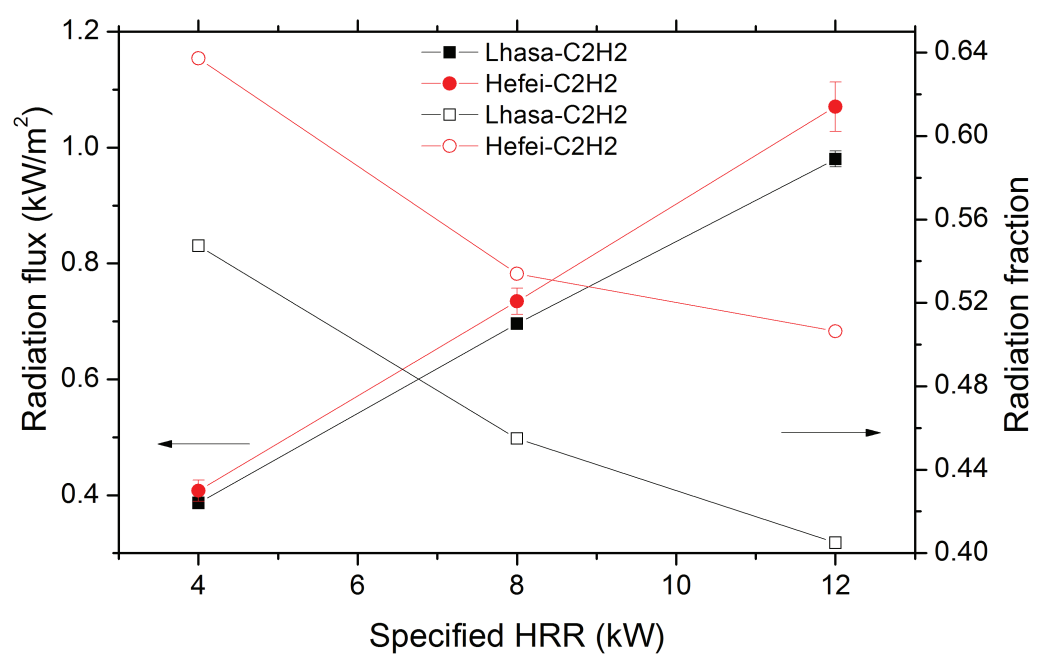

(b)

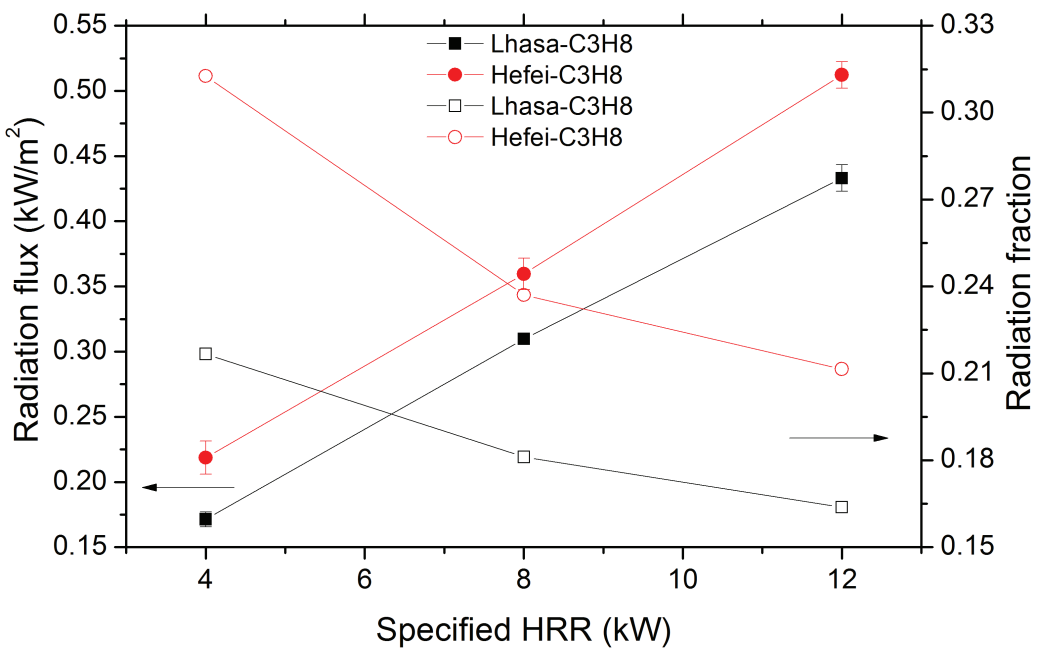

(c)

FIG. 5: Radiation flux and radiation fraction: (a) methane fires, (b) acetylene fires, (c) propane fires 
gaseous jet fire and solid box fire tests at these two altitudes (Yang, 2012; Yao, 2013). Only methane fire measurements were presented as the soot deposited on the thermocouples made the measurements for ethylene and propane fires impossible. The higher combustion efficiency at a lower pressure implies that more heat was released and hence the axial temperature was raised in Lhasa. The lower air density at lower pressure means that the flame fronts will shift to a higher location to entrain more oxygen for the combustion (Hu et al., 2013), therefore the peak temperature of methane fires occurred at around $0.2 \mathrm{~m}$ in Lhasa tests, while the peak temperature occurred at around $0.1 \mathrm{~m}$ in Hefei tests and then the axial temperature decreased upward.

\subsection{Radiation Flux}

Figure 5 plots the measured radiation fluxes of all fires and their corresponding flame radiation fractions at both low and normal pressures. Flame radiation fraction can be calculated by using the measured overall radiation flux as follows:

$$
\chi_{r}=\frac{\dot{Q}_{r}}{\dot{Q}}=\frac{q_{r} 4 \pi R^{2}}{\dot{Q}}
$$

where $\dot{Q}_{r}$ is the total radiation flux emitted from the flame, $q_{r}$ is the overall radiation flux per unit area measured by the radiometer, and $R$ is the distance from the flame center to the radiometer. The radiative heat fluxes at a low pressure are lower than those at normal pressure, which is consistent with the previous finding in Fang et al. (2011). Since the heat release rates are higher at a low pressure, the radiation fractions become even lower in Lhasa, especially for the acetylene fires. Higher radiation flux and radiation fraction in Hefei are due to the increased soot formation at a higher pressure (Intasopa, 2011; Roditcheva and Bai, 2001).

\subsection{Light Extinction Coefficient}

The light extinction coefficient is the most widely measured quantity to characterize the smoke tendency of the flame, and it can be derived from transmittance through the exhaust duct (Mulholland, 2002). According to Bouguer's law, the light extinction coefficient $K$ is related to the incident light intensity $I_{0}$, the received light intensity $I$, and the optical path length $L$ :

$$
K=-\ln \left(I / I_{0}\right) / L
$$

where the transmittance $I / I_{0}$ is measured directly by the photoelectric kapnometer. Methane and propane fires produced negligible smoke obscuration because of their low smoke emitting tendencies (Berry and Roberts, 2006; Kent, 1986). So only the transmittances of acetylene fires at the two pressures are presented in Fig. 6, where it can be seen that the transmittances in Lhasa were greater than those in Hefei. Correspondingly the light extinction coefficients of the exhausted smoke of acetylene fires in Lhasa were smaller than those in Hefei. The observation that smoke yield in Lhasa was weaker is consistent with the previous results of acetylene fires (Yang, 2012) and $n$-heptane pool fires (Hu et al., 2011). The lower smoke yield also increases the combustion efficiency in Lhasa.

\section{CONCLUSIONS}

In this study, the heat release rate and radiative heat flux for methane, acetylene, and propane fires at two altitudes were experimentally measured to reveal the influence of low pressure on combustion efficiency and 


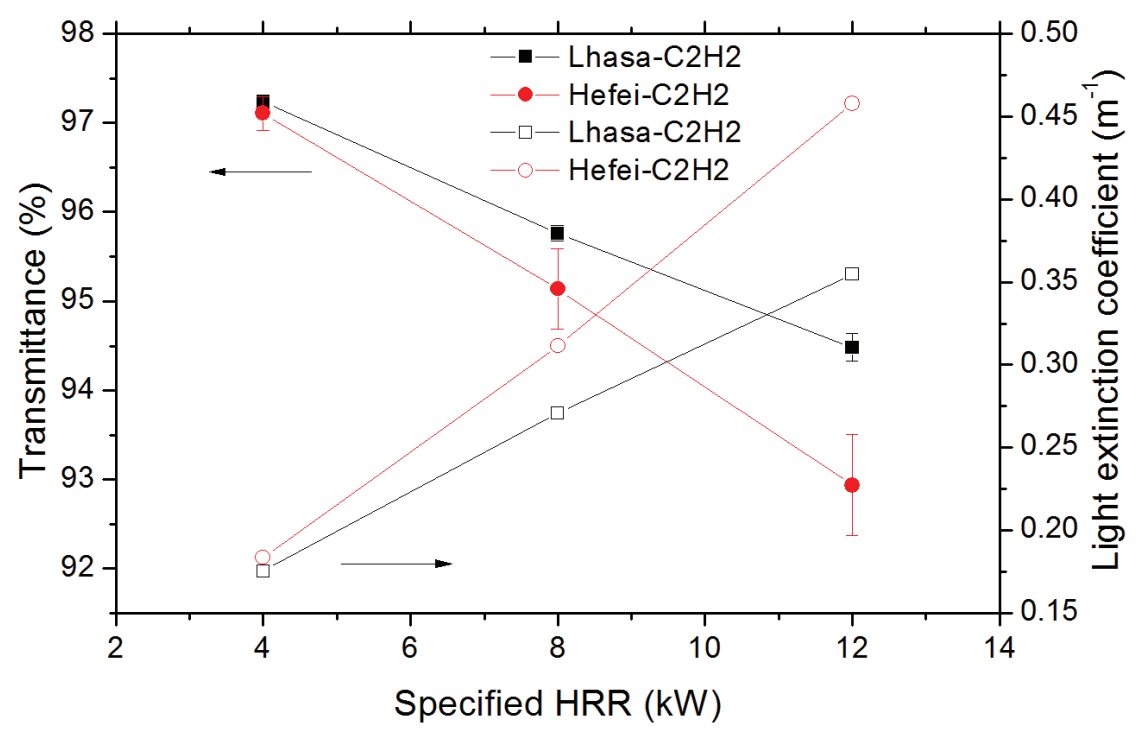

FIG. 6: Transmittance and light extinction coefficient of acetylene fires

radiation fraction. A simplified thermochemistry technique based on concentrations of $\mathrm{O}_{2}$ and $\mathrm{CO}_{2}$ for calculating heat release rate was proposed.

The heat release rate and combustion efficiency were found to be higher at a lower pressure for all the three fuels studied. The overall plume temperatures of methane fires were higher at a lower pressure. The radiative heat fluxes and radiation fractions were lower at a lower pressure. The transmittances of acetylene fires were greater at lower pressure implying that smoke yield at a low pressure was smaller. In summary, the findings in this paper contribute to a better understanding of the influence of pressure on fire behaviors, especially for actual heat release rates of the same burning rate, and provide data for fire protection in high altitude environment.

\section{ACKNOWLEDGMENT}

This research was supported by the General Program of National Natural Science Foundation of China (No. 51376172).

\section{REFERENCES}

Berry, T.L. and Roberts, W.L., Measurement of smoke point in velocity-matched coflow laminar diffusion flames with pure fuels at elevated pressures, Combust. Flame, vol. 145, pp. 571-578, 2006.

Bourguignon, E., Johnson, M.R., and Kostiuk, L.W., The use of a closed-loop wind tunnel for measuring the combustion efficiency of flames in a cross flow, Combust. Flame, vol. 119, pp. 319-334, 1999.

Enright, P.A., Heat release and the combustion behaviour of upholstered furniture, PhD Thesis, University of Canterbury, 1999.

Fang, J., Tu, R., Guan, J.F., Wang, J.J., and Zhang, Y.M., Influence of low air pressure on combustion characteristics and flame pulsation frequency of pool fires, Fuel, vol. 90, pp. 2760-2766, 2011.

Hamins, A., Klassen, M., Gore, J., and Kashiwagi, T., Estimate of flame radiance via a single location measurement in liquid pool fires, Combust. Flame, vol. 86, pp. 223-228, 1991.

Hu, L., Wang, Q., Tang, F., Delichatsios, M., and Zhang, X., Axial temperature profile in vertical buoyant turbulent jet fire in a reduced pressure atmosphere, Fuel, vol. 106, pp. 779-786, 2013. 
Hu, X., He, Y., Li, Z., and Wang, J., Combustion characteristics of $n$-heptane at high altitudes, Proc. Combust. Inst., vol. 33, pp. 2607-2615, 2011.

Intasopa, G., Soot Measurements in High-Pressure Diffusion Flames of Gaseous and Liquid Fuels, Master's Thesis, University of Toronto, 2011.

Janssens, M., Calorimetry, in: P. J. DiNenno (Ed.), The SFPE Handbook of Fire Protection Engineering, 3rd ed., National Fire Protection Association, Quincy, MA 02269, pp. 3-43, 2002.

Jun, F., Yu, C.Y., Ran, T., Qiao, L.F., Zhang, Y.M., and Wang, J.J., The influence of low atmospheric pressure on carbon monoxide of $n$-heptane pool fires, J. Hazardous Mater, vol. 154, pp. 476-483, 2008.

Kent, J.H., A quantitative relationship between soot yield and smoke point measurements, Combust. Flame, vol. 63, pp. 349$358,1986$.

Koseki, H. and Mulholland, G.W., The effect of diameter on the burning of crude oil pool fires, Fire Technol., vol. 27, pp. 54-65, 1991.

Li, Z.H., He, Y., Zhang, H., and Wang, J., Combustion characteristics of n-heptane and wood crib fires at different altitudes, Proc. Combust. Inst., vol. 32, pp. 2481-2488, 2009.

Markstein, G.H., Relationship between smoke point and radiant emission from buoyant turbulent and laminar diffusion flames, Proc. Symposium (Int.) on Combustion, vol. 20, pp. 1055-1061, 1985.

Mulholland, G.W., Smoke Production and Properties, in: P. J. DiNenno (Ed.), The SFPE Handbook of Fire Protection Engineering, 3rd ed., National Fire Protection Association, Quincy, MA 02269, pp. 2-263, 2002.

Nikitin, Y.V., Variations of mass combustion rate with oxygen concentration and gas pressure of a Milieu, J. Fire Sci., vol. 16, pp. 458-467, 1998.

Roditcheva, O.V. and Bai, X.S., Pressure effect on soot formation in turbulent diffusion flames, Chemosphere, vol. 42, pp. 811-821, 2001.

ISO 9705: 1993 Fire Tests - Full-Scale Room Test for Surface Products, International Organization for Standardization, 1993.

Tao, C., Cai, X., and Wang, X., Experimental determination of atmospheric pressure effects on flames from small-scale pool fires, J. Fire Sci., vol. 31, pp. 387-394, 2013.

Tewarson, A., Generation of Heat and Chemical Compounds in Fires, in: P. J. DiNenno (Ed.), The SFPE Handbook of Fire Protection Engineering, 3rd ed., National Fire Protection Association, Quincy, MA 02269, pp. 3/102-3/103, 2002.

Tewarson, A., Combustion efficiency and its radiative component, Fire Safety J., vol. 39, pp. 131-141, 2004.

Wieser, D., Jauch, P., and Willi, U., The influence of high altitude on fire detector test fires, Fire Safety J., vol. 29, pp. 195-204, 1997.

Yang, M., He, Y., Li, H., Zhang, X., Li, Z., and Wang, J., Combustion of laminar non-premixed acetylene jet at two different altitudes, Combust. Sci. Technol., vol. 184, pp. 1950-1969, 2012.

Yao, W., Hu, X., Rong, J., Wang, J., and Zhang, H., Experimental study of large-scale fire behavior under low pressure at high altitude, J. Fire Sci., vol. 31, pp. 481-494, 2013.

Yin, J., Yao, W., Liu, Q., Zhou, Z., Wu, N., Zhang, H., Lin, C.H., Wu, T., and Meier, O.C., Experimental study of $n$-heptane pool fire behavior in an altitude chamber, Int. J. Heat Mass Transfer, vol. 62, pp. 543-552, 2013.

Volume 48, Issue 10, 2017 
